\title{
Association between obesity indices and blood pressure or hypertension: which index is the best?
}

\author{
Ziqiang Zhou ${ }^{1, *}$, Dayi Hu ${ }^{2}$ and Jie $\mathrm{Chen}^{3}$ \\ ${ }^{1}$ Cardiovascular Center, Beijing Tongren Hospital, Affiliate of Capital Medical University, Dongjiaominxiang \# 1 , \\ Dongcheng District, Beijing 100730, People's Republic of China: ${ }^{2}$ Heart Center, People's Hospital of Peking \\ University, Beijing, People's Republic of China: ${ }^{3}$ Department of Epidemiology and Statistics, People's Hospital of \\ Peking University, Beijing, People's Republic of China
}

Submitted 29 April 2008: Accepted 18 July 2008: First published online 9 September 2008

\begin{abstract}
Background: The association between obesity and blood pressure is well documented and a series of obesity indices are used as risk factors or indicators of blood pressure and/or the presence of hypertension.

Objective: The aim of the present study was to explore and determine which obesity index is the best indicator of blood pressure and the presence of hypertension among five frequently used simple anthropometric indices.

Methods: Subjects ( $n$ 29 079) were selected by cluster sampling from fourteen Chinese general populations. Weight, height, waist circumference (WC), hip circumference and blood pressure were measured for each participant. BMI, waist:hip ratio (WHR), waist:stature ratio (WSR) and conicity index (CI) were calculated. Pearson correlation, multiple logistic regression, multivariate linear regression and receiver-operating characteristic (ROC) curve analyses were used. Results: A total of 13558 men and 15521 women were investigated. All five obesity indices were positively correlated with blood pressures and hypertension. After adjusting for age, WSR in men and BMI in women had the greatest association with the presence of hypertension, irrespective of the statistical method used. BMI had the strongest correlation with continuous blood pressures in both genders.

Conclusion: The present results indicate that hypertension is associated with different obesity indices in men and in women. The best indicator for hypertension is WSR in men while it is BMI in women.
\end{abstract}

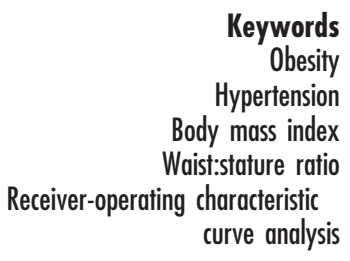

eywords

Obesity

Body mass index

Waist:stature ratio

curve analysis
Hypertension and obesity are both very important issues in primary care in the 21st century and have become two growing worldwide epidemics ${ }^{(1,2)}$. Many epidemiological studies have shown a progressive increase in the prevalence of elevated blood pressure or hypertension with increasing obesity ${ }^{(3-9)}$. A series of anthropometric indices were used as obesity measures in these studies, including BMI, waist:hip ratio (WHR), waist circumference (WC), waist:stature ratio (WSR) and conicity index (CI). However, it is not yet fully clear which anthropometric index of obesity has the strongest association with hypertension.

BMI has been most frequently used in many epidemiological studies as a measure of body fatness ${ }^{(3-11)}$. Also, several studies have indicated that BMI is highly correlated with overall obesity but relatively poorly with visceral obesity (central obesity, android-type obesity or abdominal adiposity) ${ }^{(12)}$, which tends to be more closely associated with blood pressure and/or hypertension ${ }^{(6-10,13)}$. Thus there is a need to find other obesity indices better associated with visceral obesity. WC, WHR and WSR were measured and calculated to meet this need, and have been shown to be strongly correlated with prevalent CHD and other associated disorders independent of BMI, or even better than $\mathrm{BMI}^{(11)}$. Another index to measure abdominal adiposity is the $\mathrm{CI}^{(14)}$, introduced in 1991 by Valdez, who claimed that CI has several advantages over WHR. Ho et al. reported that WSR was more strongly associated with cardiovascular risk factors than other simple anthropometric indices among Hong Kong Chinese adults ${ }^{(15)}$. Savva et al. indicated that WSR and WC were both better associated with CVD risk factors than BMI in children ${ }^{(16)}$. Although recently there have been several valuable articles focused on the issue of which obesity index is best associated with blood pressure and hypertension $^{(17-21)}$, they were limited by either small sample size or inadequate consideration of obesity measures.

In order to explore and compare the association between different obesity indices and blood pressure and presence of hypertension, we used the data from a large, population-based epidemiological study $^{(22)}$ and chose five different anthropometric indices as obesity measures: BMI, WSR, WC, WHR and CI. The reasons for choosing these five indices were: (i) they are easily obtained without 
expensive or complex instruments; (ii) they are conveniently self-measurable; and (iii) they have been frequently used in many previous epidemiological studies.

\section{Subjects and methods}

Fourteen centres based on fourteen populations from thirteen provinces across China were established, which were able to represent the average standards of living, education and health care in mainland China. Based on data from the local household registration system in each cohort, subjects were selected by cluster random sampling from each established population. There was no significant heterogeneity across these sites. Each participating centre was responsible for 2000 to 2500 subjects (born in or before 1972) and the ratio of male participants to female was required to be 1:1. Selected subjects were asked from their homes to come to the appointed place for examinations and interviews. Approval for all protocols of the present study was obtained from the review board of the Health Ministry of the People's Republic of China. A regular hospital or health agency in each area was appointed to provide equipment and venues for the study to perform examinations and interviews. All participants received a detailed introduction to the study by local government and medical organizations, which included appointed hospitals, centres for disease control and prevention, and the health departments in local governments. The informed consent was obtained from participants by local medical organizations. All examinations for participants were free and no participant was paid.

\section{Antbropometry}

The researchers (including physicians as interviewers and technicians as assistants) from each participating centre were gathered and received unified training before the survey started, in order that the same standards of measurements were used across the centres.

Weight was measured with a pointer spring balance to the nearest $0 \cdot 1 \mathrm{~kg}$. Height was measured to the nearest $1 \mathrm{~cm}$ using a non-stretchable tape measure. WC was measured at the midpoint between the bottom of the ribs and the top of the iliac crest. Hip circumference was measured at the largest posterior extension of the buttocks. Both WC and hip circumference were measured to the nearest $1 \mathrm{~cm}$ with an inelastic tape. All anthropometric measures were taken in the fasting state, with the participants dressed in light clothing and without shoes. Every morning, the spring balance was calibrated with a standard weight. BMI, WSR and WHR were calculated using the following formulas:

$$
\begin{aligned}
& \mathrm{BMI}=\frac{\operatorname{weight}(\mathrm{kg})}{\operatorname{height}^{2}\left(\mathrm{~m}^{2}\right)}, \\
& \mathrm{WSR}=\frac{\mathrm{WC}(\mathrm{cm})}{\text { height }(\mathrm{cm})}
\end{aligned}
$$

and

$$
\mathrm{WHR}=\frac{\mathrm{WC}(\mathrm{cm})}{\text { hip circumference }(\mathrm{cm})} .
$$

CI was determined through the measurements of weight, height and WC, using the following formula ${ }^{(14)}$ :

$$
\mathrm{CI}=\frac{\mathrm{WC}(\mathrm{m})}{0 \cdot 109 \times \sqrt{\text { weight }(\mathrm{kg}) / \text { height }(\mathrm{m})}} .
$$

\section{Blood pressure measurements}

Each participant's blood pressure was measured in the right arm at sitting position using a standardized mercury column sphygmomanometer with a standardized proto$\mathrm{Col}^{(23)}$. The participants rested for at least $10 \mathrm{~min}$ in seated position before the measurements, with their arm supported at the level of the heart. All subjects wore light clothing (no tight clothing constricting the arm) and were in optimal room conditions. Smokers were required to stop smoking for at least $15 \mathrm{~min}$ before blood pressure was measured. No stimulant drink, such as tea, coffee or alcohol, was allowed within $30 \mathrm{~min}$ before blood pressure was taken. Each participant's blood pressure was measured three times with a 2 min interval between measurements. The mean of the three readings was accepted as the final value. Systolic blood pressure (SBP) was accepted as the first Korotkoff sound phase and diastolic blood pressure (DBP) as the fifth phase (disappearance of sounds) to the nearest $2 \mathrm{mmHg}$. Three different cuff sizes were used on the participants according to their arm circumference (small adult $=12 \mathrm{~cm} \times 23 \mathrm{~cm}$ for $<25 \mathrm{~cm}$; standard adult $=15 \mathrm{~cm} \times 30 \mathrm{~cm}$ for $25-35 \mathrm{~cm}$; large adult $=18 \mathrm{~cm} \times 36 \mathrm{~cm}$ for $>35 \mathrm{~cm}$ ) as per the recommendations of the Chinese Hypertension League ${ }^{(24)}$. Cases of hypertension were defined as $\mathrm{SBP} \geq 140 \mathrm{mmHg}$ or $\mathrm{DBP} \geq$ $90 \mathrm{mmHg}$ or use of blood pressure-lowering drugs.

\section{Data collection}

Each participant was required to respond to an interviewerled questionnaire especially designed for the survey. The questionnaires were all recorded by the trained interviewers based on face-to-face interviews. The interviewers obtained demographic details, recorded the family medical history and education level, and inquired about smoking and alcohol drinking habits. Medical history of diabetes, hypertension, dyslipidaemia and hyperthyroidism was selfreported. Participants did not take blood tests for blood sugar, blood lipids or thyroid function. Participants were categorized as smokers if they were current smokers or former smokers and as non-smokers if they never smoked; and categorized as users (current or former) or non-users (never) regarding their alcohol usage.

\section{Statistical analysis}

Statistical analyses were performed mostly using the SPSS for Windows statistical software package version $15 \cdot 0$ 
(SPSS Inc., Chicago, IL, USA). Descriptive statistics for obesity indices were calculated for both men and women. Differences in continuous variables between genders were tested with Student's $t$ test, including age, SBP, DBP, WC, BMI, WSR, WHR and CI. Differences in binomial categorized variables between men and women were analysed with Pearson's $\chi^{2}$ test, including hyperthyroidism (yes/no), educated (yes/no), smoking (yes/no), hypertension (yes/no), drinking (yes/no), diabetes (yes/ no), dyslipidaemia (yes/no), SBP $\geq 140 \mathrm{mmHg}$ (yes/no) and $\mathrm{DBP} \geq 90 \mathrm{mmHg}$ (yes/no). Correlation coefficients between WC, BMI, WSR, WHR and CI were calculated by Pearson correlation analyses.

Because anthropometric indices (continuous) are highly correlated with each other, they were tested separately in multiple backward stepwise logistic regression models after adjusting for age (continuous), hyperthyroidism, education, smoking, hypertension, drinking, diabetes and dyslipidaemia. Due to high multicollinearity, they were not considered as independent variables in the same regression model with hypertension (yes/no) as the dependent variable. Obesity indices were then categorized as quadrinomial variables using their quartiles as cut-off points and tested separately again in multiple backward stepwise logistic regression models using the first quartile as reference category. After categorization, obesity measures were also put into the same regression models to test their independent relationship with the presence of hypertension, because multicollinearity between categorized indices was thought to be not as strong as that between continuous indices.

Multivariate linear stepwise regression was performed to analyse the association of each obesity index with SBP (continuous) or DBP (continuous) as dependent variable, respectively, after adjustment for age (continuous), hyperthyroidism, education, smoking, hypertension, drinking, diabetes and dyslipidaemia. Again, anthropometric indices for obesity were not tested together in a same regression model due to high multicollinearity.

Receiver-operating characteristic (ROC) curve analysis was performed with the Medcalc program version $9 \cdot 3 \cdot 9 \cdot 0$ (MedCalc Software, Mariakerke, Belgium). The ROC curve is a plot of the sensitivity $v$. 1-specificity for each cut-off value.

Area under the curve (AUC) was calculated both directly and after adjustment for age. The AUC is an indicator of how well the anthropometric indices for obesity can distinguish the presence of hypertension, elevated SBP or elevated DBP. Results from ROC curve analysis could be used for inter-verification with those from the multivariate regression model. Pairwise comparisons between AUC were performed using the $Z$ test. SBP and DBP were categorized into binomial variables by the cut-off value of $140 \mathrm{mmHg}$ and $90 \mathrm{mmHg}$, respectively. When ROC curve analyses for DBP and SBP were performed, 4905 cases taking antihypertensive medicine were excluded because their blood pressure may not reflect the real value. Exact confidence intervals were calculated by StatPages.net (http://statpages.org/confint. html) based on binomial distribution. All $P$ values reported are two-tailed and $P<0.05$ was considered to be statistically significant.

\section{Results}

The present cross-sectional study investigated 29079 subjects (mean age 52.5 (SD 22.4) years, range 30-100 years), including 13558 men and 15521 women. The response rate was about $96 \%$. The most common reason for non-participation ( $4 \%$ ) was due to refusal of examination. Male subjects were significantly older than female subjects (53.3 (SD 11.6) years $v .51 .9$ (SD 11.3) years, $P<0 \cdot 001)$. The anthropometric obesity indices, demographic characteristics and disease variables of the study population are shown in Table 1.

The correlations between obesity indices were all very strong ( $r>\sim 0 \cdot 70$; see Table 2 ), except for correlations of BMI with WHR $(r=0.331, P<0.001$ among women; $r=0.442, \quad P<0 \cdot 001$ among men) and BMI with CI ( $r=0 \cdot 236, P<0 \cdot 001$ among women; $r=0 \cdot 227, P<0 \cdot 001$ among men).

Multiple backward stepwise logistic regression analyses were performed using WC, BMI, WSR, CI and WHR as the independent variable, respectively, and hypertension (yes/no) as the dependent variable to test the association between each obesity measure and hypertension. The results are shown in Table 3 as odds ratios not adjusted, adjusted only for age, and adjusted for age, smoking, education, drinking, hyperthyroidism, dyslipidaemia and diabetes. Whether with adjustment or without, the order of OR for obesity indices regarding the presence of hypertension was WSR (per 0.01) $>$ WHR (per $0 \cdot 01)>$ WC $($ per $1 \mathrm{~cm})>$ CI (per 0.01) $>$ BMI (per $0 \cdot 1 \mathrm{~kg} /$ $\mathrm{m}^{2}$ ) in men and WSR (per $\left.0 \cdot 01\right)>$ WC $($ per $1 \mathrm{~cm})>$ WHR $($ per $0 \cdot 01)>C$ I $($ per $0 \cdot 01)>B M I\left(\right.$ per $\left.0.1 \mathrm{~kg} / \mathrm{m}^{2}\right)$ in women. However, if the measurement unit of BMI was set to $1 \mathrm{~kg} / \mathrm{m}^{2}$ instead of $0 \cdot 1 \mathrm{~kg} / \mathrm{m}^{2}$, the OR for BMI increased markedly and became the largest one.

Next, the five obesity indices were transformed into quadrinomial categorized variables using their quartiles as cut-off points and entered logistic regression analyses again using the first quartile as reference value. The results are given in Table 4 . Without adjustment, the orders were $\mathrm{WSR}>\mathrm{WC}>\mathrm{CI}>\mathrm{BMI}>\mathrm{WHR}$ in men and WSR $>$ WC $>$ BMI $>$ CI $>$ WHR in women. After adjusting for age only or age and other factors, the order became $\mathrm{WSR}>\mathrm{WC}>\mathrm{BMI}>\mathrm{CI}>\mathrm{WHR}$ in men and $\mathrm{BMI}>\mathrm{WSR}>$ $\mathrm{WC}>\mathrm{WHR}>\mathrm{CI}$ in women. Similar trends to the above results would be found if the five obesity indices (as quartiles) were entered into the same logistic regression model (detailed tables not shown). 
Table 1 The anthropometric indices, demographic characteristics and prevalence of diseases in men and women: subjects ( $n$ 29 079) from fourteen Chinese general populations, mainland China

\begin{tabular}{|c|c|c|c|c|c|}
\hline & \multicolumn{2}{|c|}{ Men ( $n$ 13558) } & \multicolumn{2}{|c|}{ Women (n 15521) } & \multirow[b]{2}{*}{$P$ value } \\
\hline & $\begin{array}{l}\text { Prevalence or } \\
\text { proportion (\%) }\end{array}$ & $\begin{array}{c}95 \% \text { confidence } \\
\text { interval }\end{array}$ & $\begin{array}{l}\text { Prevalence or } \\
\text { proportion (\%) }\end{array}$ & $\begin{array}{c}95 \% \text { confidence } \\
\text { interval }\end{array}$ & \\
\hline Hyperthyroidism & 0.53 & $0.42,0.67$ & $1 \cdot 88$ & $1 \cdot 67,2 \cdot 11$ & $<0.001$ \\
\hline Educatedt & 38.9 & $38 \cdot 08,39 \cdot 73$ & $29 \cdot 88$ & $29 \cdot 16,30 \cdot 01$ & $<0.001$ \\
\hline Smoking & $68 \cdot 84$ & $68 \cdot 06,69 \cdot 62$ & $6 \cdot 81$ & $6 \cdot 42,7 \cdot 22$ & $<0.001$ \\
\hline Hypertension & 36.96 & $36 \cdot 15,37 \cdot 78$ & 34.95 & $34 \cdot 20,35 \cdot 70$ & $<0.001$ \\
\hline Drinking & $63 \cdot 86$ & $63 \cdot 04,64 \cdot 68$ & $10 \cdot 75$ & $10 \cdot 26,11 \cdot 24$ & $<0.001$ \\
\hline Diabetes & $3 \cdot 31$ & $3 \cdot 05,3 \cdot 67$ & $3 \cdot 70$ & $3 \cdot 41,4 \cdot 01$ & 0.069 \\
\hline Dyslipidaemia & $11 \cdot 34$ & $10 \cdot 81,11 \cdot 89$ & $11 \cdot 50$ & $11 \cdot 00,12 \cdot 01$ & 0.675 \\
\hline $\operatorname{SBP}(\geq 140 \mathrm{mmHg})$ & $25 \cdot 37$ & $24 \cdot 64,26 \cdot 11$ & $25 \cdot 82$ & $25 \cdot 13,26 \cdot 51$ & 0.387 \\
\hline \multirow[t]{2}{*}{ DBP $(\geq 90 \mathrm{mmHg})$} & $19 \cdot 57$ & $18 \cdot 90,20 \cdot 25$ & $13 \cdot 83$ & $13 \cdot 29,14 \cdot 39$ & $<0.001$ \\
\hline & Mean & SD & Mean & SD & \\
\hline Age (years) & $53 \cdot 3$ & $11 \cdot 6$ & $51 \cdot 9$ & $11 \cdot 3$ & $<0.001$ \\
\hline $\mathrm{SBP}(\mathrm{mmHg})$ & $129 \cdot 5$ & $19 \cdot 2$ & $127 \cdot 4$ & $21 \cdot 8$ & $<0.001$ \\
\hline $\mathrm{DBP}(\mathrm{mmHg})$ & $80 \cdot 5$ & $11 \cdot 3$ & $77 \cdot 4$ & $11 \cdot 2$ & $<0.001$ \\
\hline Hip circumference $(\mathrm{cm})$ & $95 \cdot 5$ & $8 \cdot 8$ & $96 \cdot 8$ & 8.9 & $<0.001$ \\
\hline Height $(\mathrm{cm})$ & $167 \cdot 53$ & $6 \cdot 98$ & $156 \cdot 05$ & $6 \cdot 75$ & $<0.001$ \\
\hline Weight (kg) & $68 \cdot 48$ & $10 \cdot 98$ & $59 \cdot 64$ & $9 \cdot 79$ & $<0.001$ \\
\hline WC $(\mathrm{cm})$ & $84 \cdot 7$ & $9 \cdot 8$ & $80 \cdot 9$ & $10 \cdot 2$ & $<0.001$ \\
\hline BMI $\left(\mathrm{kg} / \mathrm{m}^{2}\right)$ & $24 \cdot 33$ & $3 \cdot 20$ & $24 \cdot 45$ & 3.55 & 0.002 \\
\hline WSR & 0.506 & 0.058 & 0.519 & 0.066 & $<0.001$ \\
\hline WHR & 0.877 & 0.063 & 0.835 & 0.066 & $<0.001$ \\
\hline $\mathrm{Cl}$ & $1 \cdot 219$ & 0.096 & $1 \cdot 204$ & $0 \cdot 105$ & $<0.001$ \\
\hline
\end{tabular}

SBP, systolic blood pressure; DBP, diastolic blood pressure; WC, waist circumference; WSR, waist:stature ratio; WHR, waist:hip ratio; $\mathrm{Cl}$, conicity index. tEducated $=$ high school attainment or further.

Table 2 Pearson correlation coefficients between anthropometric obesity indices among subjects ( $n$ 29079) from fourteen Chinese general populations, mainland China

\begin{tabular}{|c|c|c|c|c|c|c|}
\hline & & WC & BMI & WSR & WHR & $\mathrm{Cl}$ \\
\hline \multirow[t]{4}{*}{ Women } & WC & - & 0.740 & 0.948 & 0.669 & 0.809 \\
\hline & BMI & 0.740 & - & 0.729 & 0.331 & 0.236 \\
\hline & WSR & 0.948 & 0.729 & - & 0.683 & 0.817 \\
\hline & WHR & 0.669 & 0.331 & 0.683 & - & 0.731 \\
\hline \multirow[t]{4}{*}{ Men } & WC & - & 0.746 & 0.938 & 0.713 & 0.797 \\
\hline & BMI & 0.746 & - & 0.719 & 0.442 & 0.227 \\
\hline & WSR & 0.938 & 0.719 & - & 0.726 & 0.817 \\
\hline & WHR & 0.713 & 0.442 & 0.726 & - & 0.693 \\
\hline
\end{tabular}

WC, waist circumference; WSR, waist:stature ratio; WHR, waist:hip ratio; $\mathrm{Cl}$, conicity index.

Each coefficient was statistically significant: $P<0.001$.

Table 5 presents the correlation coefficients of obesity measures with blood pressure. Multivariate linear stepwise regression analysis was used with SBP and DBP as the continuous dependent variable, respectively. Before this analysis, we excluded 4905 subjects with hypertension who took antihypertensive medicine regularly or irregularly. Both in men and in women, the orders of correlation with SBP and DBP were $\mathrm{BMI}>\mathrm{WC}>\mathrm{WSR}>$ WHR $>$ CI. In men BMI was positively correlated with $(\beta=0.264)$ and explained $18.7 \%$ of the variance in SBP, followed by WC $(17 \cdot 2 \%)$ and WHR $(14 \cdot 2 \%)$, while both CI $(13 \cdot 3 \%)$ and WSR $(13 \cdot 2 \%)$ explained a similar amount of variance; BMI was also most correlated with DBP in men $(\beta=0 \cdot 323)$ and explained more variance $(12 \cdot 0 \%)$ than any other obesity index. In women, the order of amount of SBP variance explained was $\mathrm{BMI}>\mathrm{WSR}>$ WC $>$ WHR $>$ CI, where BMI $(\beta=0.265)$ explained $26 \cdot 3 \%$ of the variance in SBP; and the order for DBP was $\mathrm{BMI}>\mathrm{WC}>\mathrm{WSR}>\mathrm{WHR}>\mathrm{CI}$, where $\mathrm{BMI}(\beta=0 \cdot 311)$ explained $11.5 \%$ of the variance in DBP. All obesity measures were significantly $(P<0 \cdot 001)$ and positively associated with blood pressure.

AUC in men and women are listed in Table 6 and the $P$ values of pairwise comparisons are listed in Table 7. ROC analyses for associations between the five indices and hypertension are shown in Fig. 1 for men and Fig. 2 for women.

In men, ROC curve analyses showed that AUC of WSR for hypertension was always the largest among the five anthropometric indices whether adjusted for age or not. However, pairwise comparison indicated that the difference between AUC of WSR and WC for hypertension was not statistically significant $(0.737 v .0 .735, P=0.066)$. When SBP was used as the classification variable with cutoff point $\geq 140 \mathrm{mmHg}$ or DBP was used with cut-off point $\geq 90 \mathrm{mmHg}$, WSR had the largest AUC for SBP and DBP without adjustment for age. After adjusting for age, however, AUC of WSR was slightly lower than that of WC for DBP (0.668 v. 0.670, $P=0.594)$ and slightly higher than AUC of BMI $(0.665, P=0.545)$, both differences being statistically insignificant. AUC of WSR for hypertension and SBP were still significantly higher than the AUC of any other index after adjustment for age. 
Table 3 Crude and adjusted odds ratios for hypertension according to different obesity measures among subjects $(n 29079)$ from fourteen Chinese general populations, mainland China

\begin{tabular}{|c|c|c|c|c|c|c|}
\hline & \multicolumn{2}{|c|}{ Crude } & \multicolumn{2}{|c|}{ Adjustedt } & \multicolumn{2}{|c|}{ Adjusted $\ddagger$} \\
\hline & OR & $\begin{array}{c}95 \% \text { confidence } \\
\text { interval }\end{array}$ & OR & $\begin{array}{l}95 \% \text { confidence } \\
\text { interval }\end{array}$ & OR & $\begin{array}{l}95 \% \text { confidence } \\
\text { interval }\end{array}$ \\
\hline \multicolumn{7}{|l|}{ Men } \\
\hline WC (per $1 \mathrm{~cm})$ & $1 \cdot 067$ & $1 \cdot 063,1 \cdot 072$ & $1 \cdot 068$ & $1 \cdot 063,1.072$ & $1 \cdot 054$ & $1 \cdot 050,1 \cdot 059$ \\
\hline BMI $\left(\right.$ per $\left.0.1 \mathrm{~kg} / \mathrm{m}^{2}\right)$ & $1 \cdot 016$ & $1 \cdot 015,1 \cdot 018$ & $1 \cdot 019$ & $1 \cdot 018,1 \cdot 020$ & $1 \cdot 018$ & $1 \cdot 017,1 \cdot 019$ \\
\hline WSR (per 0.01) & $1 \cdot 134$ & $1 \cdot 126,1 \cdot 142$ & $1 \cdot 123$ & $1 \cdot 115,1 \cdot 131$ & $1 \cdot 112$ & $1 \cdot 104,1 \cdot 120$ \\
\hline WHR (per 0.01) & $1 \cdot 070$ & $1 \cdot 064,1 \cdot 077$ & $1 \cdot 069$ & $1 \cdot 062,1 \cdot 075$ & $1 \cdot 062$ & $1 \cdot 055,1 \cdot 069$ \\
\hline $\mathrm{Cl}($ per 0.01) & $1 \cdot 058$ & $1.053,1.062$ & $1 \cdot 045$ & $1 \cdot 041,1.050$ & 1.040 & $1 \cdot 036,1 \cdot 045$ \\
\hline BMI (per $\left.1 \mathrm{~kg} / \mathrm{m}^{2}\right)$ & $1 \cdot 178$ & $1 \cdot 164,1 \cdot 192$ & $1 \cdot 214$ & $1 \cdot 198,1 \cdot 229$ & $1 \cdot 195$ & $1 \cdot 180,1 \cdot 211$ \\
\hline \multicolumn{7}{|l|}{ Women } \\
\hline WC (per $1 \mathrm{~cm})$ & $1 \cdot 076$ & $1 \cdot 072,1 \cdot 080$ & $1 \cdot 060$ & $1 \cdot 055,1 \cdot 064$ & $1 \cdot 062$ & $1 \cdot 057,1 \cdot 066$ \\
\hline BMI (per $\left.0.1 \mathrm{~kg} / \mathrm{m}^{2}\right)$ & $1 \cdot 019$ & $1 \cdot 018,1 \cdot 020$ & $1 \cdot 019$ & $1 \cdot 018,1 \cdot 020$ & $1 \cdot 018$ & $1 \cdot 016,1 \cdot 019$ \\
\hline WSR (per 0.01) & $1 \cdot 131$ & $1 \cdot 124,1 \cdot 138$ & $1 \cdot 092$ & $1 \cdot 086,1.099$ & $1 \cdot 084$ & $1.077,1.091$ \\
\hline WHR (per 0.01) & $1 \cdot 067$ & $1.061,1.073$ & $1 \cdot 037$ & $1 \cdot 031,1.043$ & $1 \cdot 033$ & $1 \cdot 027,1.039$ \\
\hline $\mathrm{Cl}$ (per 0.01) & $1 \cdot 055$ & $1 \cdot 051,1 \cdot 059$ & $1 \cdot 023$ & $1 \cdot 019,1 \cdot 027$ & $1 \cdot 019$ & $1 \cdot 015,1 \cdot 023$ \\
\hline BMI (per $1 \mathrm{~kg} / \mathrm{m}^{2}$ ) & $1 \cdot 205$ & $1 \cdot 193,1 \cdot 218$ & $1 \cdot 204$ & $1 \cdot 191,1 \cdot 217$ & $1 \cdot 190$ & $1 \cdot 176,1 \cdot 203$ \\
\hline
\end{tabular}

WC, waist circumference; WSR, waist:stature ratio; WHR, waist:hip ratio; $\mathrm{Cl}$, conicity index.

Each OR was statistically significant: $P<0 \cdot 001$.

tAdjusted for age.

$\ddagger$ Adjusted for age, smoking, education, drinking, hyperthyroidism, dyslipidaemia and diabetes.

In women, if not adjusted for age, AUC of WSR was still larger than that of any other index, while after adjustment for age BMI had the largest AUC for all three classification variables and the differences were all statistically significant.

\section{Discussion}

As early as 1967, data from the Framingham Study indicated that obesity is a leading risk factor for chronic arterial hypertension ${ }^{(25)}$. Several previous studies have tried to find which anthropometric index correlates most closely with blood pressure and incidence or prevalence of hypertension, when used to define obesity. Mark et al. found that the prevalence of elevated blood pressure was positively correlated with increasing adipose tissue ${ }^{(17)}$. Fuchs et al. reported that WC was a very important screening tool for elevated blood pressure in a crosssectional study, though still less important than $\mathrm{BMI}^{(19)}$. Also, a longitudinal study with relatively small sample reported by Fuchs et al. indicated that the correction of waist by stature or hip circumference improved its prediction of the incidence of hypertension, even better than that for $\mathrm{BMI}^{(19)}$. However, these studies involved fewer obesity measures than the present study and were not able to fully solve the question.

Only two previous studies explored the association of all five simple anthropometric obesity indices with blood pressure and hypertension ${ }^{(20,21)}$. The most recent one was conducted in Singapore, in which Ghosh and Bandyopadhyay claimed that BMI, WSR and WC had stronger correlations than other anthropometric indices with both SBP and DBP as continuous variables ${ }^{(21)}$. Similar trends could be seen in the present study. Ghosh and Bandyopadhyay tried to compare the relationship of obesity measures with the presence of hypertension using multiple logistic regression models and found that BMI was associated with greater risk of hypertension. As seen in our results (Table 3), however, the OR for obesity measures highly depends on the size of the measurement unit when the logistic regression model is used. BMI's association with hypertension became the weakest among obesity indices if its measurement unit was set to $0 \cdot 1 \mathrm{~kg} / \mathrm{m}^{2}$ and the strongest with $1 \mathrm{~kg} / \mathrm{m}^{2}$ per measurement. That is, the OR for a continuous variable increases with the size of measurement unit in the logistic regression analysis. Therefore, without a standard measurement unit for each obesity index being clearly and reasonably defined, direct comparison between obesity measures based on OR value becomes invalid or at least less convincing. In the present study, besides the method used in Table 3, we transformed each obesity measure into a categorical variable by its quartiles to avoid the issue related to the measurement unit and then made a comparison using a logistic regression model. Thus we found that WSR rather than BMI was the best indicator for hypertension in men and BMI was best associated with hypertension in women after adjusting for age and/or other risk factors. Moreover, this result was in agreement with that from ROC curve analysis.

Results from three studies which investigated the same five obesity measures are listed in Table 8; they include the study from Cambridge by Yalcin et al. ${ }^{(18)}$, Ghosh and Bandyopadhyay ${ }^{(21)}$ and the present study. In spite of the obviously small sample size of the two previous studies, all three studies indicated BMI, WSR and WC to have stronger correlations with both SBP and DBP in both genders. In fact, compared with the two previous studies, the order of correlation between obesity measures and 


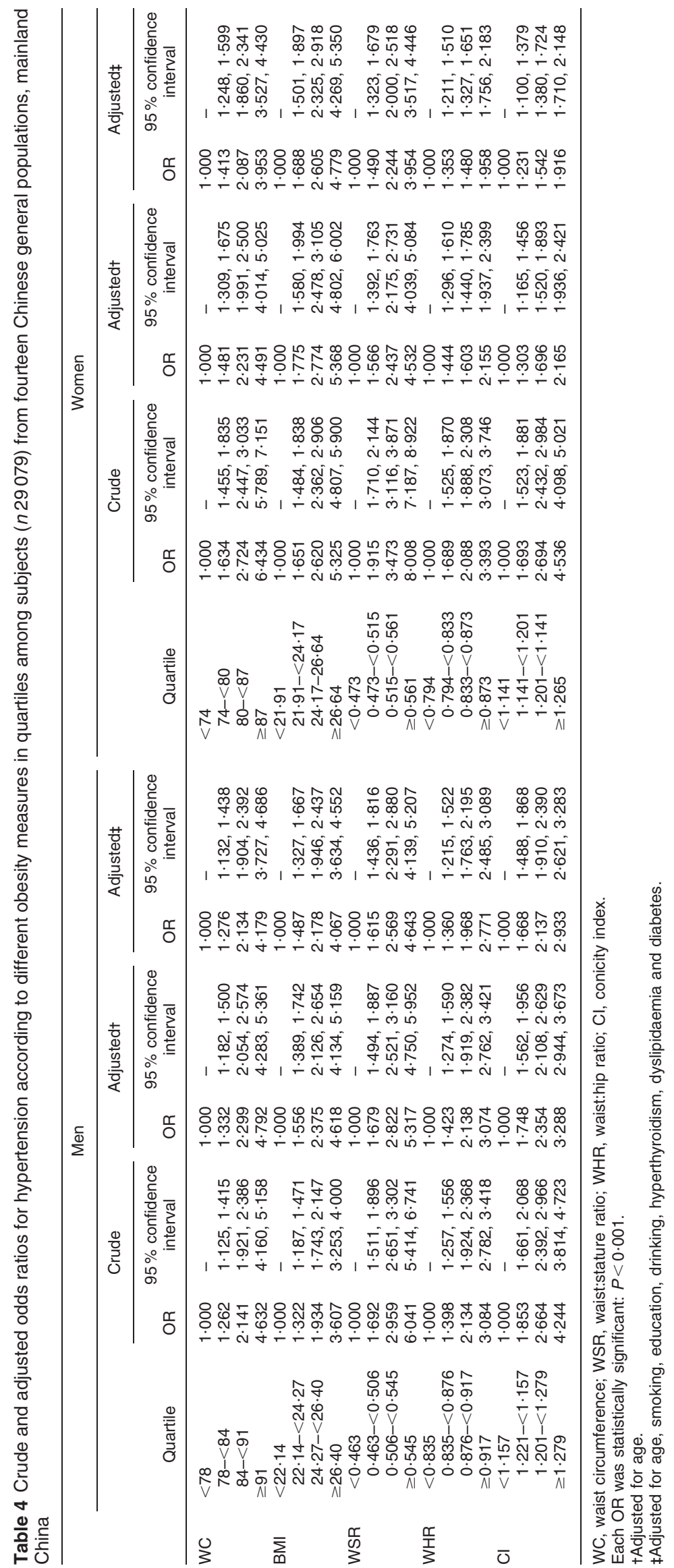


Table 5 Multivariate linear stepwise regression analysis of obesity measures with blood pressure among subjects ( $n$ 24174) from fourteen Chinese general populations, mainland China

\begin{tabular}{|c|c|c|c|c|c|c|}
\hline & \multicolumn{3}{|c|}{ SBP } & \multicolumn{3}{|c|}{ DBP } \\
\hline & $\beta$ & $R^{2}$ & $P$ & $\beta$ & $R^{2}$ & $P$ \\
\hline \multicolumn{7}{|l|}{ Men } \\
\hline BMI & 0.264 & 0.187 & * & 0.323 & $0 \cdot 12$ & * \\
\hline WC & 0.236 & 0.172 & * & 0.291 & $0 \cdot 101$ & * \\
\hline WSR & 0.212 & 0.132 & * & 0.269 & 0.088 & * \\
\hline WHR & $0 \cdot 15$ & 0.142 & * & $0 \cdot 176$ & 0.051 & * \\
\hline $\mathrm{Cl}$ & 0.118 & 0.133 & * & 0.133 & 0.037 & * \\
\hline \multicolumn{7}{|l|}{ Women } \\
\hline BMI & 0.265 & 0.263 & * & 0.311 & 0.115 & * \\
\hline WC & 0.227 & 0.221 & * & 0.267 & 0.085 & * \\
\hline WSR & 0.226 & 0.237 & * & 0.241 & 0.071 & * \\
\hline WHR & $0 \cdot 109$ & 0.206 & * & 0.114 & 0.034 & * \\
\hline $\mathrm{Cl}$ & 0.082 & 0.201 & * & 0.083 & 0.028 & * \\
\hline \multicolumn{7}{|l|}{ Both } \\
\hline BMI & 0.254 & 0.193 & * & 0.304 & 0.11 & * \\
\hline WC & 0.225 & 0.178 & * & 0.281 & 0.093 & * \\
\hline WSR & 0.212 & 0.172 & * & 0.232 & 0.068 & \\
\hline WHR & $0 \cdot 14$ & 0.148 & * & $0 \cdot 165$ & 0.044 & . \\
\hline $\mathrm{Cl}$ & 0.096 & 0.139 & * & $0 \cdot 106$ & 0.029 & * \\
\hline
\end{tabular}

SBP, systolic blood pressure; DBP, diastolic blood pressure; WC, waist circumference; WSR, waist:stature ratio; WHR, waist:hip ratio; $\mathrm{Cl}$, conicity index. ${ }^{*} P<0.001$

hypertension in our study is more consistent between different groups, which may be due to three reasons: (i) the sample size in the present study was large; and/or (ii) in order to avoid multicollinearity from which Yalcin's study suffered ${ }^{(18)}$, all five obesity indices in the present study were tested in multivariate linear stepwise regression models separately adjusted for other factors. On the other hand, (iii) considering the small sample size and potential problem in statistics in the two previous studies, conclusions made in the present study should be more reliable, although results in the mentioned two studies are in agreement with each other in men (see Table 8). However, it should be noted that results from both ROC curve and logistic regression analyses in the present study showed that the 'strongest' obesity measure for hypertension in men is WSR rather than BMI. In our analysis with the linear stepwise regression model, 4905 patients with hypertension were excluded in order to get rid of the confounding effects of antihypertensive drugs on blood pressure. Excluding these participants who potentially contained information related to hypertension, however, may in turn have compromised the results to some extent. Despite this possibility, results in our study are still convincing due to the large sample size and because they do not suffer from multicollinearity. Furthermore, the obesity measure that most closely correlates with continuous change of blood pressure per $1 \mathrm{mmHg}$ may not have the same strong association with the presence of hypertension. Further data, especially from large-scale prospective studies, are still needed to verify the relationships and the correlation orders.

ROC curves are frequently used to compare the diagnostic performance of two or more laboratory or diagnostic

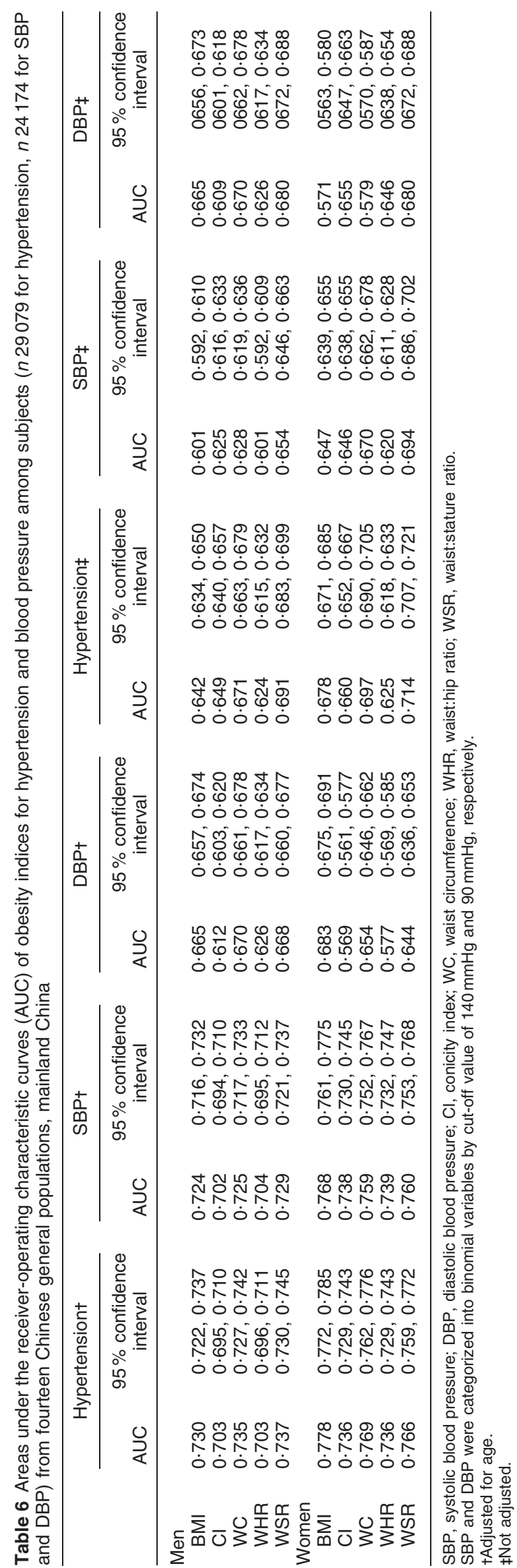


Table $7 P$ values in pairwise comparisons of areas under the receiver-operating characteristic curve between anthropometric obesity indices for different classification variables among subjects ( $n 29079$ for hypertension, $n 24174$ for SBP and DBP) from fourteen Chinese general populations, mainland China

\begin{tabular}{|c|c|c|c|c|c|c|c|c|c|c|c|}
\hline \multirow[b]{2}{*}{ Classification variable } & & \multicolumn{5}{|c|}{ Men } & \multicolumn{5}{|c|}{ Women } \\
\hline & & BMI & $\mathrm{Cl}$ & WC & WHR & WSR & BMI & $\mathrm{Cl}$ & WC & WHR & WSR \\
\hline \multirow[t]{4}{*}{ Hypertensiont } & $\mathrm{BMI}$ & - & * & 0.066 & * & 0.005 & - & * & * & * & * \\
\hline & $\mathrm{Cl}$ & * & - & * & $0 \cdot 814$ & * & * & - & * & 0.705 & * \\
\hline & WC & 0.066 & * & - & * & 0.037 & * & * & - & * & 0.003 \\
\hline & WHR & * & 0.814 & * & - & * & * & 0.705 & * & - & \\
\hline \multirow[t]{4}{*}{ SBPt } & $\mathrm{BMI}$ & - & & $0 \cdot 708$ & * & * & - & * & * & * & 0.002 \\
\hline & $\mathrm{Cl}$ & * & - & * & 0.445 & * & * & - & * & 0.303 & * \\
\hline & WC & $0 \cdot 708$ & * & - & * & 0.008 & * & * & - & * & 0.338 \\
\hline & WHR & * & 0.445 & * & - & & * & 0.303 & * & - & * \\
\hline \multirow[t]{4}{*}{ DBPt } & BMI & - & * & 0.371 & * & 0.545 & - & * & * & * & * \\
\hline & $\mathrm{Cl}$ & * & - & * & * & & * & - & * & $0 \cdot 169$ & * \\
\hline & WC & 0.371 & * & - & 0.012 & 0.594 & * & * & - & * & * \\
\hline & WHR & * & 0.012 & * & - & * & * & 0.169 & * & - & * \\
\hline \multirow[t]{4}{*}{ Hypertension } & $\mathrm{BMI}$ & - & 0.322 & * & 0.001 & * & - & 0.002 & * & * & * \\
\hline & $\mathrm{Cl}$ & 0.322 & - & * & * & * & 0.002 & - & * & * & * \\
\hline & WC & * & * & - & * & * & * & * & - & * & * \\
\hline & WHR & * & 0.001 & * & - & * & * & * & * & - & * \\
\hline \multirow[t]{4}{*}{ SBP $\ddagger$} & BMI & - & 0.003 & * & * & * & - & 0.933 & * & * & * \\
\hline & $\mathrm{Cl}$ & 0.003 & - & 0.482 & 0.976 & * & 0.933 & - & * & * & * \\
\hline & WC & & 0.482 & - & * & * & * & * & - & * & * \\
\hline & WHR & 0.976 & * & * & - & * & * & * & * & - & * \\
\hline \multirow[t]{4}{*}{ DBP $\ddagger$} & $\mathrm{BMI}$ & - & * & 0.351 & * & 0.729 & - & * & * & * & * \\
\hline & $\mathrm{Cl}$ & * & - & * & 0.004 & & * & - & * & 0.195 & * \\
\hline & WC & 0.351 & 0 & - & * & 0.288 & * & * & - & * & 0.004 \\
\hline & WHR & & 0.004 & * & - & & * & 0.195 & * & - & * \\
\hline
\end{tabular}

$\mathrm{Cl}$, conicity index; WC, waist circumference; WHR, waist:hip ratio; WSR, waist:stature ratio; SBP, systolic blood pressure; DBP, diastolic blood pressure. SBP and DBP were categorized into binomial variables by cut-off value of $140 \mathrm{mmHg}$ and $90 \mathrm{mmHg}$, respectively.

${ }^{\star} P<0.001$.

tAdjusted for age.

$\ddagger$ Not adjusted.

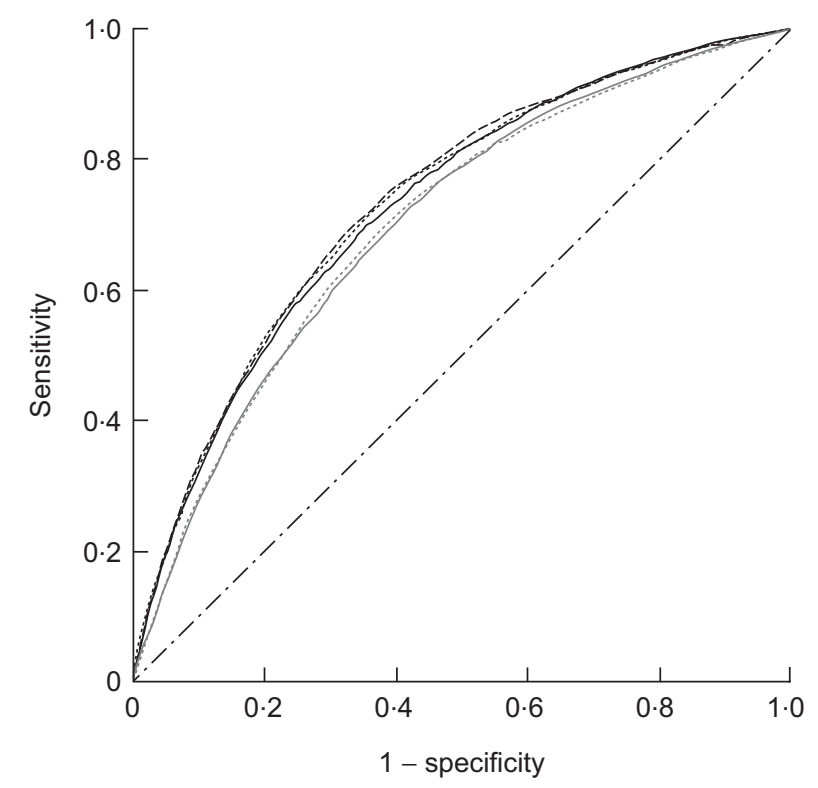

Fig. 1 Receiver-operating characteristic curves of obesity indices (circumference; -........., waist:hip ratio; -------, waist:stature ratio) for hypertension among male subjects ( $n$ 13558) from fourteen Chinese general populations, mainland China...$--\cdot$ indicates area under the curve of 0.5 (line indicating no discriminative capability)

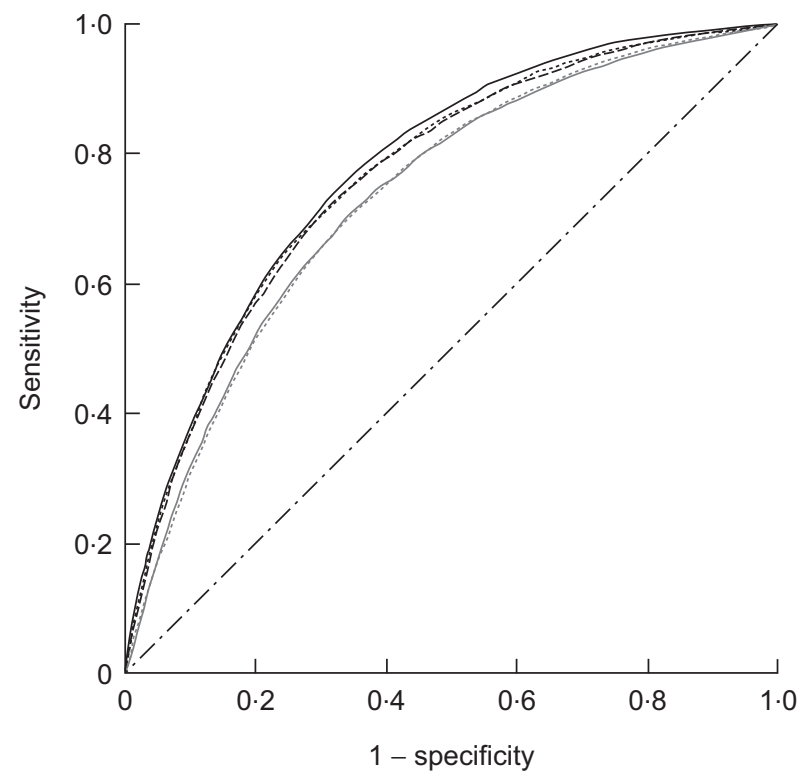

Fig. 2 Receiver-operating characteristic curves of obesity indices (- $\longrightarrow$ BMI; — circumference; -......---., waist:hip ratio; -------, waist:stature ratio) for hypertension among female subjects ( $n$ 15521) from fourteen Chinese general populations, mainland China. - . - - indicates area under the curve of 0.5 (line indicating no discriminative capability) 
Obesity indices, blood pressure and hypertension

Table 8 Comparison of correlation orders of obesity measures with blood pressure

\begin{tabular}{|c|c|c|c|c|}
\hline & & Present study ( $n$ 29 079) & Yalcin et al. ${ }^{(18)}(n$ 267) & Ghosh \& Bandyopadhyay $^{(21)}(n$ 180) \\
\hline SBP & Men & $\begin{array}{l}\mathrm{BMI}>\mathrm{WC}>\mathrm{WSR}>\mathrm{WHR}>\mathrm{Cl} \\
\mathrm{BMI}>\mathrm{WC}>\mathrm{WSR}>\mathrm{WHR}>\mathrm{Cl}\end{array}$ & 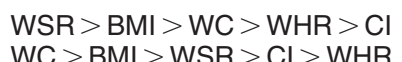 & $\mathrm{WSR}>\mathrm{BMI}>\mathrm{WC}>\mathrm{WHR}>\mathrm{Cl}$ \\
\hline DBP & $\begin{array}{l}\text { Men } \\
\text { Women }\end{array}$ & $\begin{array}{l}\mathrm{BMl}>\mathrm{WC}>\mathrm{WSR}>\mathrm{WHR}>\mathrm{Cl} \\
\mathrm{BMl}>\mathrm{WC}>\mathrm{WSR}>\mathrm{WHR}>\mathrm{Cl}\end{array}$ & $\begin{array}{l}\mathrm{BMI}>\mathrm{WC}>\mathrm{WSR}>\mathrm{WHR}>\mathrm{Cl} \\
\mathrm{WC}>\mathrm{WSR}>\mathrm{Cl}>\mathrm{WHR}>\mathrm{BMI}\end{array}$ & $\mathrm{BMI}>\mathrm{WC}>\mathrm{WSR}>\mathrm{WHR}>\mathrm{Cl}$ \\
\hline
\end{tabular}

WC, waist circumference; WSR, waist:stature ratio; WHR, waist:hip ratio; $\mathrm{Cl}$, conicity index; SBP, systolic blood pressure; DBP, diastolic blood pressure.

tests, and were first used by Ho et al. in 2003 to select the best index in relation to cardiovascular risks, including hypertension, SBP and $\mathrm{DBP}^{(15)}$. Ho et al. reported in their study that WSR was more strongly associated with hypertension, SBP and DBP than other simple anthropometric indices. Unfortunately however, the results were not adjusted for age, which may render the conclusion invalid. As listed in Tables 6 and 7, results in the present study showed in both men and women that the AUC of WSR was significantly the largest for hypertension, SBP and DBP before adjusting for age; but after adjustment for age, AUC of WSR was the largest only in men and second to that of BMI in women.

In the present study, WSR in men and BMI in women had the closest correlation with the presence of hypertension, and these results were very consistent across two logistic regression models (with obesity indices as continuous or categorized variables) and ROC curve analyses. This major difference between the two sexes was never reported before. Many previous studies ${ }^{(6-10,13)}$ indicated that visceral obesity measured by WC or WHR was more closely associated with blood pressure and/or the presence of hypertension than overall obesity measured by BMI; while a study in 1992 claimed that BMI had a better correlation with blood pressure in both men and women ${ }^{(26)}$. Most of these studies were limited by relatively small sample size and almost all of them suffered from multicollinearity in statistical analysis with either a logistic regression model or a linear stepwise regression model. Moreover, none of them performed important ROC curve analysis to explore the predictive value of these anthropometric indices for hypertension. This may partly explain why they could not reveal the major difference between the genders. One previous study based on a Hong Kong Chinese population ${ }^{(27)}$ reported that types of obesity of men and women were clearly different according to WHR and BMI, but the authors did not perform further analysis between obesity measures and blood pressure as done in our study. Moreover, in our study, all obesity measures as quartiles in the same logistic regression model also supported that WSR and BMI rather than WC had stronger correlation with hypertension. WSR has been proved to be a good indicator of abdominal visceral fat ${ }^{(28)}$ and cardiovascular risk factors ${ }^{(15)}$, while BMI is by far a good indicator for overall adiposity ${ }^{(12)}$. Consequently, the present results indicate that men's hypertension depends mainly on visceral obesity and women's hypertension correlates mainly with overall adiposity.

Furthermore, the linear regression coefficients for each obesity measure with continuous SBP or DBP were substantially greater in men than in women, suggesting a greater male responsiveness of blood pressure to a gain in relative weight or abdominal deposition. This result is totally different from that in the study by Doll et al. ${ }^{(7)}$, where women had a greater responsiveness than did men. The two studies were both cross-sectional but they were not based on the same ethnic groups. Also, Doll did not consider the effect of collinearity between obesity measures. The two factors may partly explain the differences.

The present study had a very large sample size, which made it possible to perform statistical analyses using more than one method and made the results more convincing. Consistent results from different statistical methods, including logistic regression models and ROC curve analyses, contributed to the reliability of the findings. Moreover, multicollinearity between obesity measures was avoided in statistical analysis to a large extent. However, the present study also has some limitations. First, histories of diseases were self-reported and no blood test was performed. Second, although the sample size was very large, the population studied was limited to Chinese in China mainland. Therefore we could not obtain results across different ethnic groups. Besides, the limitation of the crosssectional design was also a fact in our study. The relative ratio of anthropometric indices for blood pressures and incidence of hypertension could not be calculated. Longitudinal studies with large sample size and a follow-up with the present study are needed to further explore these questions.

\section{Conclusion}

All anthropometric indices for obesity were positively correlated with blood pressure and the presence of hypertension in this representative Chinese sample. After adjusting for age or for age and other factors, WSR in men and BMI in women had a greater association with hypertension than other simple obesity measures. Therefore we may infer that WSR for males and BMI for females should be recommended as good predictors for hypertension. BMI had the strongest correlation with continuous blood pressures in both genders. There exists 
a major difference between men and women, which has never been revealed by previous studies, regarding the issue of which obesity measure is the best indicator for hypertension. We may not hope to use a universal good indicator of obesity for hypertension and/or blood pressure in both genders. Visceral obesity tends to be more important in men with regard to hypertension, while in women the better indicator for hypertension should be overall obesity.

\section{Acknowledgements}

We would like to thank all study researchers, participants, partners and the staff of participating general practices for their support and interest in the study. Many thanks to the staff in all study centres from Guangdong, Hebei, Henan, Hubei, Hunan, Inner Mongolia, Shandong, Shanxi, Sichuan, Tianjin, Yunan and Zhejiang provinces; to Drs Renhan Zhang, Kuibao Li and Xiuli Zhao for acting as monitors during the screening work; to both Beijing Tongren Hospital and People's Hospital for their support; and to Drs Chuzhong Tang and Lihua Shang for providing assistance during the study. Special thanks to the Ministry of Health in the People's Republic of China for funding the project (no. WKZ-2001-1-08). The corresponding author declares that all thanks are presented in the acknowledgement and no conflicts of interest exist in this study.

Author contributions: Z.Z., D.H. and J.C. designed and supervised the research. Z.Z. and J.C. performed data checking work and statistical analyses. Z.Z. and D.H. did main preparation work for the paper. Z.Z. and J.C. acted as monitors during the screening work.

\section{References}

1. Flegal KM, Carroll MD, Ogden CL \& Johnson CL (2002) Prevalence and trends in obesity among US adults, 1999-2000. JAMA 288, 1723-1727.

2. Mokdad AH, Ford ES, Bowman BA, Dietz WH, Vinicor F, Bales VS \& Marks JS (2003) Prevalence of obesity, diabetes, and obesity-related health risk factors, 2001. JAMA 289, 76-79.

3. Lamon-Fava S, Wilson PW \& Schaefer EJ (1996) Impact of body mass index on coronary heart disease risk factors in men and women - The Framingham offspring study. Arterioscler Thromb Vasc Biol 16, 1509-1515.

4. Wilson PW, D'Agostino RB, Sullivan L, Parise H \& Kannel WB (2002) Overweight and obesity as determinants of cardiovascular risk: the Framingham experience. Arch Intern Med 162, 1867-1872.

5. Okosun IS, Chandra KM, Choi S, Christman J, Dever GE \& Prewitt TE (2001) Hypertension and type 2 diabetes comorbidity in adults in the United States: risk of overall and regional adiposity. Obes Res 9, 1-9.

6. Siani A, Cappuccio FP, Barba G, Trevisan M, Farinaro E, Lacone R, Russo O, Russo P, Mancini M \& Strazzullo P (2002) The relationship of waist circumference to blood pressure: the Olivetti Heart Study. Am J Hypertens 15, 780-786.

7. Doll S, Paccaud F, Bovet P, Burnier M \& Wietlisbach V (2002) Body mass index, abdominal adiposity and blood pressure: consistency of their association across developing and developed countries. Int J Obes Relat Metab Disord 26, $48-57$.

8. Dyer AR, Liu K, Walsh M, Kiefe C, Jacobs DR Jr \& Bild DE (1999) Ten-year incidence of elevated blood pressure and its predictors: the CARDIA Study Coronary Artery Risk Development in (Young) Adults. J Hum Hypertens 13, 13-21.

9. Guagnano MT, Ballone E, Colagrande V, Della Vecchia R, Manigrasso MR, Merlitti D, Riccioni G \& Sensi S (2001) Large waist circumference and risk of hypertension. Int $J$ Obes Relat Metab Disord 25, 1360-1364.

10. Kanai H, Matsuzawa Y, Kotani K, Keno Y, Kobatake T, Nagai Y, Fujioka S, Tokunaga K \& Tarui S (1990) Close correlation of intraabdominal fat accumulation to hypertension in obese women. Hypertension $\mathbf{1 6}$, 484-490.

11. Huang B, Rodreiguez BL, Burchfiel CM, Chyou PH, Curb JD \& Sharp DS (1997) Associations of adiposity with prevalent coronary heart disease among elderly men: The Honolulu heart program. Int J Obes Relat Metab Disord 21, 340-348.

12. Willett W (1990) Nutritional Epidemiology, pp. 217-244. New York: Oxford University Press.

13. Zhu S, Wang Z, Heshka S, Heo M, Faith MS \& Heymsfield SB (2002) Waist circumference and obesity-associated risk factors among whites in the third National Health and Nutrition Examination Survey: clinical action thresholds. Am J Clin Nutr 76, 743-749.

14. Valdez R (1991) A simple model-based index of abdominal adiposity. J Clin Epidemiol 44, 955-956.

15. Ho SY, Lam TH \& Janus ED, Hong Kong Cardiovascular Risk Factor Prevalence Study Steering Committee (2003) Waist to stature ratio is more strongly associated with cardiovascular risk factors than other simple anthropometric indices. Ann Epidemiol 13, 683-691.

16. Savva SC, Tornaritis M, Savva ME, Kourides Y, Panagi A, Silikiotou N, Georgiou C \& Kafatos A (2000) Waist circumference and waist-to-height ratio are better predictors of cardiovascular disease risk factors in children than body mass index. Int $J$ Obes Relat Metab Disord 24, 1453-1458.

17. Mark AL, Correia M, Morgan DA, Shaffer RA \& Haynes WG (1999) Obesity induced hypertension: new concepts from the emerging biology of obesity. Hypertension $\mathbf{3 3}$, 537-541.

18. Yalcin BM, Sahin EM \& Yalcin E (2005) Which anthropometric measurement is most closely related to elevated blood pressure? Fam Pract 22, 541-547.

19. Fuchs FD, Gus M, Moreira LB, Moraes SR, Wiehe M \& Pereira GM (2005) Anthropometric indices and the incidence of hypertension: a comparative analysis. Obes Res 13, 1515-1517.

20. Yasmin \& Mascie-Taylor CGN (2000) Adiposity indices and their relationship with some risk factors of coronary heart disease in middle aged Cambridge men and women. Ann Hum Biol 27, 239-248.

21. Ghosh JR \& Bandyopadhyay AR (2007) Comparative evaluation of obesity measures: relationship with blood pressures and hypertension. Singapore Med J 48, 232-235.

22. Zhou ZQ, Hu DY, Chen J, Zhang RH, Li KB \& Zhao XL (2004) An epidemiological survey of atrial fibrillation in China. Zhonghua Nei Ke Za Zhi 43, 491-494.

23. Weiner JS \& Lourie JA (1981) Practical Human Biology. New York: Academic Press.

24. Liu LS \& Gong LS (2000) Guidelines for prevention and treatment for hypertension in China (trial version). Chin J Hypertens 8, 94-102.

25. Kannel WB, Brand M, Skinner JJ Jr, Dawber TR \& McNamara PM (1967) The relation of adiposity to blood 
pressure and development of hypertension: the Framingham study. Ann Intern Med 67, 48-59.

26. Spiegelman D, Israel R, Bouchard C \& Willett W (1992)

Absolute fat mass, percent body fat, and body fat distribution: which is the real determinant of blood pressure and serum glucose? Am J Clin Nutr 55, 1033-1044.
27. Tanaka S \& Togo M (1990) Relationship of fat mass and fat distribution to blood pressure. Diabetes Res Clin Pract 10, Suppl. 1, S199-S203.

28. Ashwell M, Cole TJ \& Dixon AK (1996) Ratio of waist circumference to height is strong predictor of intraabdominal fat. BMJ 313, 559-560. 